\title{
BMJ Global Health Long shadow of fear in an epidemic: fearonomic effects of Ebola on the private sector in Nigeria
}

\author{
Sulzhan Bali, ${ }^{1}$ Kearsley A Stewart, ${ }^{1}$ Muhammad Ali Pate ${ }^{1,2}$
}

To cite: Bali S, Stewart KA, Pate MA. Long shadow of fear in an epidemic: fearonomic effects of Ebola on the private sector in Nigeria. BMJ Global Health 2016;1:e000111. doi:10.1136/bmjgh-2016000111

Received 21 June 2016 Accepted 28 September 2016

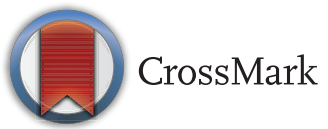

${ }^{1}$ Duke Global Health Institute, Duke University, Durham, North Carolina, USA ${ }^{2}$ BigWin Philanthropy, Washington, District of Columbia, USA

Correspondence to

Sulzhan Bali;

Sulzhan@gmail.com

\section{ABSTRACT}

Background: The already significant impact of the Ebola epidemic on Guinea, Liberia and Sierra Leone, was worsened by a fear of contagion that aggravated the health crisis. However, in contrast to other Ebolaaffected countries, Nigeria fared significantly better due to its swift containment of the disease. The objective of our study was to describe the impact of Ebola on the Nigerian private sector. This paper introduces and defines the term fearonomic effect as the direct and indirect economic effects of both misinformation as well as fear-induced aversion behaviour, exhibited by individuals, organisations or countries during an outbreak or an epidemic.

Methods: This study was designed as a crosssectional mixed-methods study that used semistructured in-depth interviews and a supporting survey to capture the impact of Ebola on the Nigerian private sector after the outbreak. Themes were generated from the interviews on the direct and indirect impact of Ebola on the private sector; the impact of misinformation and fear-based aversion behaviour in the private sector.

Results: Our findings reveal that the fearonomic effects of Ebola included health service outages and reduced healthcare usage as a result of misinformation and aversion behaviour by both patients and providers. Although certain sectors (eg, health sector, aviation sector, hospitality sector) in Nigeria were affected more than others, no business was immune to Ebola's fearonomic effects. We describe how sectors expected to prosper during the outbreak (eg, pharmaceuticals), actually suffered due to the changes in consumption patterns and demand shocks.

Conclusion: In a high-stressor epidemic-like setting, altered consumption behaviour due to distorted disease perception, misinformation and fear can trigger short-term economic cascades that can disproportionately affect businesses and lead to financial insecurity of the poorest and the most vulnerable in a society.

\section{INTRODUCTION}

The impact of fear during an infectious disease is often considerable. ${ }^{12}$ Outbreaks of infectious diseases affect nations in two distinct ways-through direct effects of the
Key questions

What is already known about this topic?

- Infectious diseases have been known to trigger fear-related behavioural changes across the public.

- The significant impact of Ebola on affected countries of Guinea, Liberia and Sierra Leone, was worsened by a fear of contagion that aggravated the health crisis.

- In contrast to other Ebola-affected countries, Nigeria contained the outbreak within 93 days.

\section{What are the new findings?}

- This study is the first to take an in-depth look at the impact of Ebola on Nigeria's private sector.

- This paper shows that even when a country swiftly controls an outbreak, there can be downstream ripple effects on its economy.

- Even sectors, which were expected to prosper during the outbreak (eg, pharmaceuticals), actually suffered due to the changes in consumption patterns and demand shocks.

\section{Recommendations for policy}

- It is necessary to address dangers of misinformation and fear-induced aversion behaviour during an outbreak. Awareness efforts should be combined with swift risk communication, quick dissemination of accurate information and synchronised response to address misinformation and stigma.

- We recommend engaging community and religious leaders and the use of tools such as social media, adverts and radio to ensure disease awareness, mobilise volunteers and to fight misinformation.

- The fearonomic effects of outbreaks should be a strong motivator for businesses to assist government efforts in epidemic response. The private sector can be a partner in building community trust in disease control efforts and in ensuring dissemination of accurate disease prevention information.

- To protect affected countries from the fearonomic effects of outbreaks, it is essential that the International Health Regulations are upheld and that countries do not restrict trade or travel against WHO advice during public health emergencies. 
disease itself, and through indirect behavioural response to the disease. ${ }^{12}$ The direct impact of a disease is captured by both the mortality and morbidity associated with the disease, as well as losses in productivity incurred as a result of the disease. At the same time, emerging infectious diseases also affect public perceptions, inducing fear and fear-related corresponding behavioural effects as occurred with AIDS, ${ }^{3}$ SARS, ${ }^{4}$ and Ebola. ${ }^{1}$ Fear can drive significant changes in human behaviour, leading to border closures and the disruption of businesses, trade, tourism and social events. ${ }^{5}$ In fact, fearrelated behavioural effects were responsible for $80-90 \%$ of the economic impact of SARS, which depressed the economic growth of affected countries by $1-5 \%$ in 2004. ${ }^{6}$ As Brazil geared up to host the 2016 Olympics, the fear of Zika had already overshadowed the benefits associated with such a landmark event. The declaration of Zika as a Public Health Emergency of International Concern (PHEIC) ${ }^{8}{ }^{9}$ follows in the immediate aftermath of another PHEIC-Ebola outbreak in West Africa, that killed over 11300 people and infected over $28000 .{ }^{10}$

The Ebola outbreak in West Africa started in December 2013 in Guinea. ${ }^{11}{ }^{12}$ By July 2014, the outbreak had spread to other neighboring West African nations, including Liberia, Sierra Leone, Nigeria, Mali, and Senegal. ${ }^{11}{ }^{12}$ The outbreak was declared a PHEIC by the WHO on 8 August 2014. ${ }^{8}$ For the first time, the downstream effects of an Ebola outbreak transcended borders of countries and continents, reminding the global health community that infectious diseases respect no borders, religion or socioeconomic status. ${ }^{13}$ The lack of timely control of Ebola revealed systemic gaps and weaknesses in global health systems, institutions and capacities regarding epidemic control. ${ }^{14}$ The impact of Ebola on affected countries of Guinea, Liberia and Sierra Leone, was worsened by a fear of contagion that aggravated the health crisis. ${ }^{6} 15{ }^{16}$ In fact, as per the World Bank estimates, the total cost of Ebola in Liberia, Guinea and Sierra Leone are estimated to be a loss of US $\$ 2.2$ billion. ${ }^{5}{ }^{17}$ However, in contrast to other Ebola-affected nations in West Africa, Nigeria fared significantly better: the Nigerian government responded to the outbreak swiftly and Nigeria was declared as Ebola-free on 20 October $2014{ }^{18}$ The economic cost incurred by Nigeria due to the Ebola outbreak was estimated to be US $\$ 186$ million. ${ }^{6}{ }^{16}$ Although significant, this amount was much less in comparison to its GDP $\left(0.5 \%\right.$ of its GDP) ${ }^{6}{ }^{16}$ It is essential to note that the Ebola outbreak in West Africa not only significantly impacted health systems and consumed health resources in the affected countries, but it also led to limited mobility, travel restrictions and disruptions across public and the private sectors. ${ }^{6} 1516$

While considerable scholarly attention has been paid to understanding and investigating the direct effects of an epidemic, our understanding of the indirect effects that arise from fear of the disease during an outbreak is limited. We investigated the impact of Ebola on Nigeria's private sector. The rapid Ebola response action by both Lagos State and the Federal governments limited the direct impact of Ebola. However, our findings shed considerable light on the role of misinformation and aversion behaviour during an outbreak. In this paper, we introduce a new term-'fearonomic effects'- that we define as the direct and the indirect economic effects of both misinformation and fear-induced aversion behaviour, exhibited by individuals, organisations or countries during an outbreak or epidemic. A focus on only the direct effects of an epidemic significantly underestimates the true cost of disease and fails to account for aversion and other fear-related consequences experienced during an epidemic. ${ }^{19}$

\section{METHODS \\ Study design and setting}

This study was designed as a cross-sectional mixedmethods study that used semistructured in-depth interviews and a supporting survey to capture the impact of Ebola on the Nigerian private sector retrospectively after the outbreak (figure 1). Data were collected in accordance with the consolidated criteria for reporting qualitative research guidelines. ${ }^{20}$ The data were collected in Lagos, Nigeria from May 2015 to September 2015. As the objective of the study was to explore and assess the holistic impact of Ebola (both direct and indirect) on the Nigerian private sector, use of qualitative methods of in-depth semistructured interview and survey was deemed appropriate.

\section{Recruitment of participants and data collection}

In-depth interviews: Snowballing and media database (LexisNexis) search was used to identify the participants to conduct in-depth interviews. We conducted keyword searches 'Nigeria', 'Ebola', 'Private sector' between 1 May 2014 and 1 May 2015. Texts reviewed included newspaper clippings and 'grey' literature. Purposive sampling was used to create the researcher's guide to key stakeholders names and economic sectors. The list was crosschecked via snowballing with key informants from our partner host organisation, Private Sector Health Alliance of Nigeria, and the public sector key informants closely involved in Nigeria's Ebola response. These experts commented on the overall impact of Ebola on the Nigerian economy and the disease's impact on the private sector from the vantage of public and private sector interactions. For this study, over 127 key informants across Nigeria were contacted via personal referrals, emails, LinkedIn, phone and in-person office visits; 114 were followed, and 76 interviews were conducted. Interviews were conducted until thematic saturation was reached. The in-depth interviews were conducted in English and lasted $\sim 60-90 \mathrm{~min}$ each. The corresponding author conducted the interviews, which were audio recorded. The interviews were mostly conducted face to face with the respondents in a comfortable setting to allow the 
Figure 1 Study Design: This study was designed as a cross-sectional mixed-methods study and conducted in Lagos, Nigeria from May to September 2015. The numbers in the figure represents the number of businesses or stakeholders interviewed (in bold) and the number of persons interviewed respectively for each sector. $\left(^{*}\right)$ Product overlap, for example, sanitizers $\left({ }^{* *}\right)$ Includes private sector hospital owned by Oil \& Gas company that serves both public sector staff and private sector staff, includes both Ebola affected hospitals in Lagos.

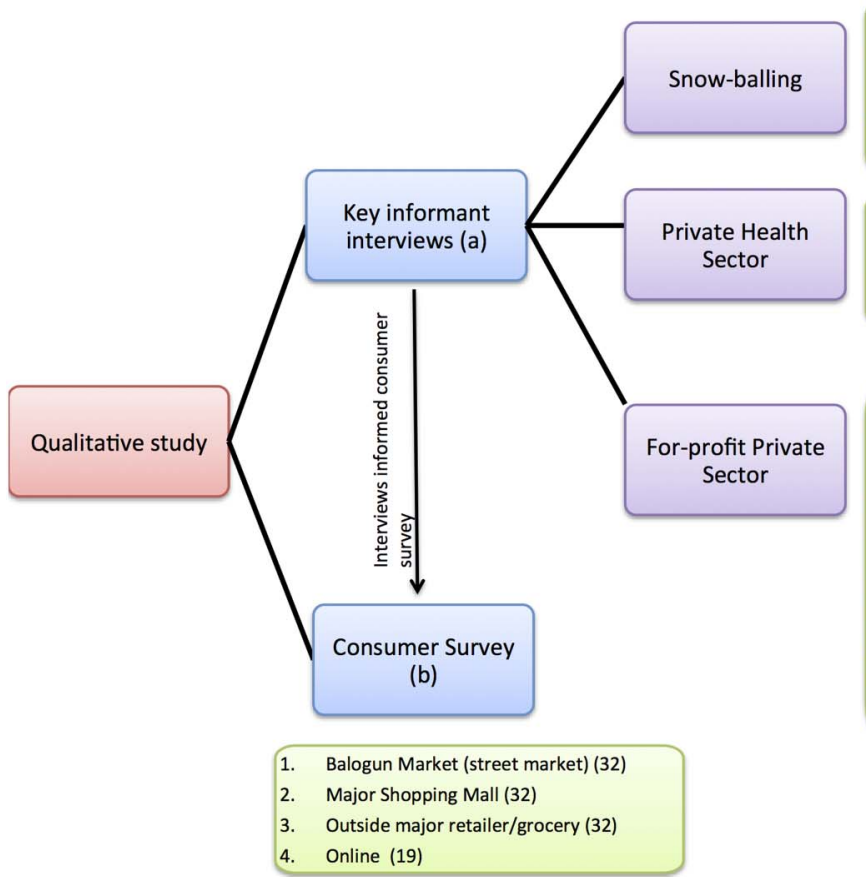

1. EEOC Staff (1)

2. Unicef (1)

3. Lagos State (1)

Federal MoH (1)

Private Sector Alliance (1)

1. Private Health Facilities $(4,11)$ **

ral Resources (6, 12)

Telecom (6, 9)

Aviation $(5,5)$

Pharmaceutical $(3,3)^{*}$

Health consumer good
manufacturer* $(2,4)$

Banks $(4,8)$

. Foundations $(7,9)$

Hotels $(3,4)$

Retailers $(3,4)^{*}$

*Some products overlapped gathering of additional information by observation as well. However, due to logistical or security constraints, nine interviews were conducted via telephone or Skype and recorded using Skype Recorder software.

Survey: The survey was designed to supplement the qualitative findings. Interim findings from the interviews informed the survey instrument, which was used to triangulate findings from the interviews from the vantage of consumers. The consumer survey also included questions regarding the perception and awareness of Ebola among the urban population in Lagos. The survey was prepared using the Qualtrics electronic survey platform. The survey was administered both online and as a paperbased questionnaire. After testing the survey, the online survey was administered via social media platforms of local Nigerian contacts. The link was live for 4 days (between 11 August and 15 August 2015) and special measures were taken to ensure retaking of the survey was not possible. While online surveys have distinct advantages in an urban metropolis setting such as that of Lagos (controlling for geographical location, ease of administering, low cost, speed), it also has disadvantages such as low response rate and a sample selection skewed to only people with internet access. To compensate for the drawbacks of an online survey, paper-based surveys were also administered across three different locations in Lagos over a span of 2 days (between 13 and 15 August 2015). Popular markets and shopping malls (Balogun market, Palms shopping mall, Spar) were chosen as the best sites to capture consumer perceptions. Convenience sampling was used to conduct the survey. However, purposive measures were taken to ensure a somewhat equitable distribution of gender and ages. Survey data was collected using structured, survey team-administered questionnaires on sociodemographic characteristics, knowledge of Ebola, perception, behavioural practices and sources of information. Forms that were more than $50 \%$ incomplete were excluded from the sample. Survey administration assistants were recruited, and three gender-balanced teams (1 girl, 1 boy) were formed to administer the paper-based surveys. The team was trained in survey administration by the author a day before the survey administration. The teams were fluent in English, local Yoruba and Pidgin dialects to increase cultural competence.

\section{Data analysis}

This thesis uses the interpretivist approach of grounded theory to analyse the qualitative data. In the grounded theory approach, interpretations are continually derived from the raw data with comparative analysis as the key themes emerge from the data. ${ }^{21}$ The processes of coding, memos and diagrams were used to analyse the data, and the data was interpreted continuously throughout the process to identify key themes and subthemes. Audio recording of the interviews were transcribed, and the text was analysed using a two-step approach. Primary coding was performed using Word. Analytic memos were written to summarise and organise the data into major themes by combining the initial coding insights for the businesses within each of the economic sectors. Relevant quotes were incorporated into the emerging themes within the memos. Key themes were allowed to emerge from the data and supplemented with literature review where appropriate. The completed memos were reviewed and uploaded to the qualitative analysis software Dedoose to enable secondary coding to identify overarching themes across sectors and ensure credibility and generalisability 
of emerging themes. Representative quotes were identified to support each of the primary themes, and the corresponding memos and transcripts for each quote were revisited to contextualise participants' words within their overall narratives. The survey data was analysed using Qualtrics and Excel as a supplement to the qualitative findings from the in-depth interviews.

\section{RESULTS}

For the in-depth interviews, $58 \%$ of the interviewees were male and $42 \%$ were female. The profiles of the interviewees were diverse, ranging from Heads of corporate communications, Directors, Government Affairs, Medical Officers, Healthcare workers, CEOs, Risk Managers, Country Directors, to HR executives. For the survey, of the 119 respondents, $55 \%$ of the respondents were male and $45 \%$ were females. About $31 \%$ of respondents were 18-24 years old, $58 \%$ were $25-39$ years old, $9 \%$ were $40-60$ years old and $2 \%$ were over 60 years old. Among the respondents, $2 \%$ had no schooling, $3 \%$ had been educated up to primary school, $22 \%$ had been educated up to secondary school level, $11 \%$ had a diploma or vocational training, $41 \%$ had undergraduate degrees, $20 \%$ had Master's degrees and 1\% had a doctoral degree.

The findings are presented according to the five themes identified: (1) The origin of fear, that is, Misinformation triggered fear and promoted high-risk behaviour; (2) The impact of fear on the economy, that is, Fearonomic effects amplified the impact of the disease on the economy; (3) The impact of fear on individuals, that is, Fearonomic effects included stigma, discrimination and collateral loss of lives; (4) The impacts of fear on the health system, that is, Fearonomic effects included the disruption of health services; and (5) The impact of fear on specific business, that is, Fearonomic effects impacted on a broad range of businesses.

\section{Misinformation triggered fear and promoted high-risk behaviour}

It was the information; the major thing at that period was the information. People were panicking more because of lack of information.-(Male, Nigerian, Corporate Affairs, Oil \& Gas)

Many people drank salt water. One of my brother's friends drank and ended up in the hospital because he was hypertensive. Luckily he didn't have a stroke.(Female, Nigerian, Head Matron at a facility in Victoria Island, Lagos)

Because we've heard so much about this disease, about how you touch somebody and you have it.-(Male, Nigerian, Business Development Executive, Pharmaceutical Sector).

From the way it was presented, its so easy to contact and spread through door handles, stairways hand rails, through mere contacts like hand shakes.-(Female, Nigerian, Sales Manager, Hospitality

This staff is okay he left today he was okay, the next day he comes to work, how are we sure he is okay, how are sure he has not touched someone that has that.(Female, GM, External Affairs \& Communication, Oil \& Gas)

Misinformation and myths regarding Ebola were fuelled by the novelty of the disease in the region, international media attention and the lack of accurate information about the disease. As Ebola was a novel disease in Nigeria, there was a significant lack of information regarding its transmission, aetiology and case management. Consequently, after the first case of Ebola was reported in Nigeria, ${ }^{11}$ social media platforms saw a sharp increase in conversations regarding Ebola. ${ }^{22}$ Social media activity fuelled rumours as people sought any available information on Ebola-whether it came from credible resources or not.

According to our survey in Lagos $(n=110)$; social media $(71 \%)$, television $(68 \%)$, radio $(47 \%)$ and friends $(52 \%)$ were the top sources of information on Ebola (figure 2). Although reliance on television and radio is similar to another study on Ebola conducted in Lagos, ${ }^{23}$ we report a higher reliance on social media. This disparity could be attributed to a higher proportion of younger respondents in our consumer perception survey (89\% were aged 18-40 years, compared to $75 \%$ in the other study) and a significantly higher proportion of postsecondary educated individuals in our sample $(73 \%$ compared to $31 \%$ in the other study). While social media can facilitate the rapid dissemination of information, its credibility may be compromised. ${ }^{22}$ Unsurprisingly, Ebola rumours circulated quickly, reflecting general panic and mistrust of political leadership. ${ }^{24}$

Almost all interviews mentioned the rumours of drinking salt water or bathing in salt water to prevent Ebola. One of the nurses interviewed mentioned how $80 \%$ of patients who came to the facility at that time confirmed that they bathed with salt and water before visiting the hospital. Rumours and misinformation about prevention and transmission of Ebola (drinking salt water, bathing in salt water, Ebola transmission from pork or suya or through touch) encouraged high-risk behaviour and created a false sense of security, which proved fatal in some cases. ${ }^{2} 222526$ Another notable example of misinformation in the Nigerian context were claims of 'holy water' touted by a Nigerian Pastor to have the ability to cure Ebola and other infectious diseases. ${ }^{27}$ Access to this 'holy water' was one of the main reasons the index patient broke quarantine to travel to Lagos, a fact that was highlighted in three separate interviews (two males and one female).

After the outbreak, the Nigerian government took strict measures to ensure that such claims were no longer made. ${ }^{28}$ Despite awareness efforts, 
Figure 2 Social media, television, and radio were top sources of information during the Ebola outbreak in Nigeria $(n=110)$. We asked respondents about how did they source their information on Ebola during the outbreak. The respondents ticked all that applied among the given choices. About $71 \%$ respondents mention social media as a source of information, $67 \%$ mentioned television as a source of information, while $52 \%$ and $47 \%$ mentioned friends and radio hosts as source of information. NGOs, non-governmental organisations.
Sources of Information on Ebola During the Outbreak

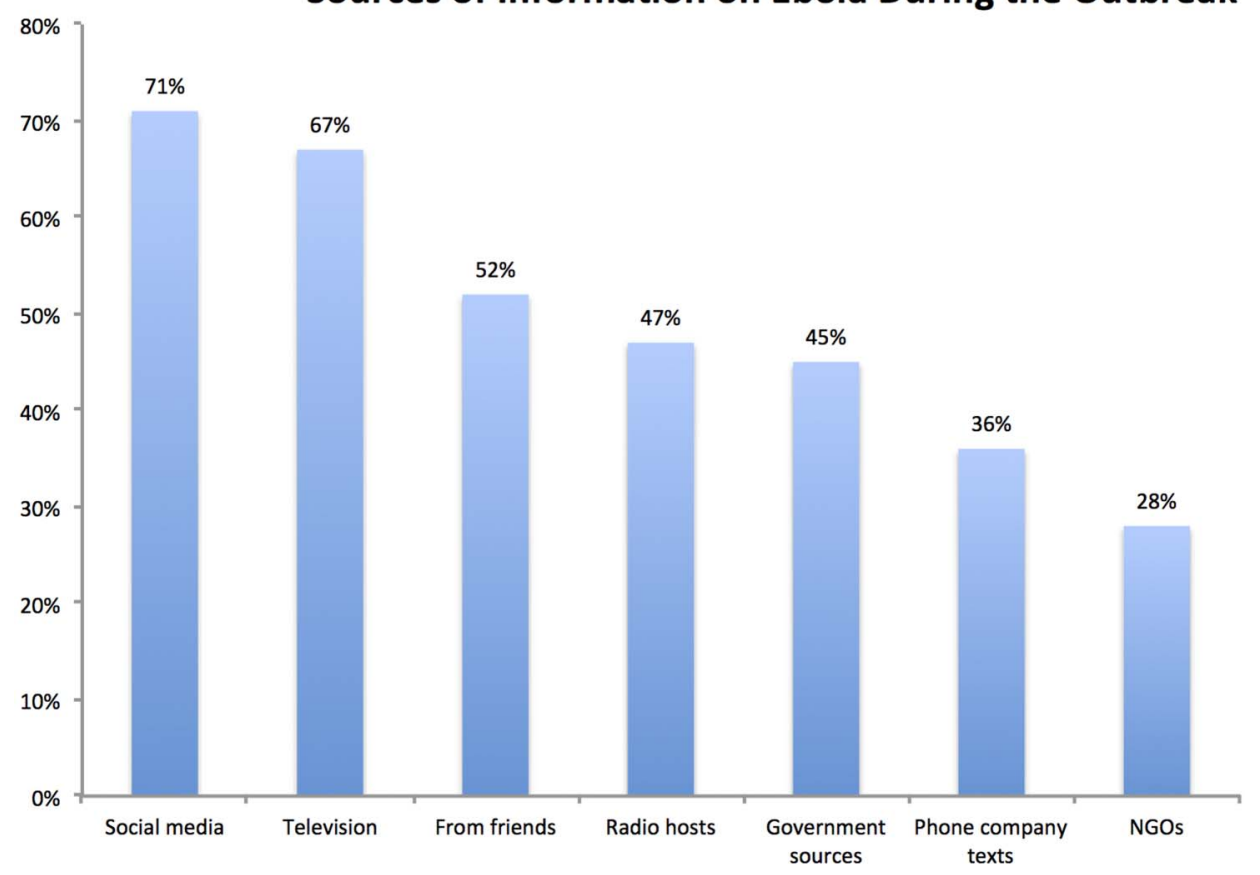

misconceptions regarding the transmission of Ebola continued to circulate. Our survey confirmed the common misconceptions that Ebola could spread via touch $(68 \%)$, pork consumption $(28 \%)$ and even air $(23 \%)$ (figure 3). For example, while some interviewees highlighted their company's awareness and disease education efforts, they went on to mention that Ebola could be transmitted from touch-evidence that misinformation is difficult to dislodge. Interviewees working in places with strong temperature checks were still worried that the disease could 'spread through door handles'. The clustering of the disease at the index hospital bolstered the belief that Ebola could be transmitted through touch. However, it is important to note that Ebola becomes highly infectious with the appearance of symptoms and ultimately spreads through body fluids. ${ }^{29} 30$

\section{Fearonomic effects amplified the impact of the disease on the economy}

But then, if you look at the effects again, a lot of businesses went down, the airline industry was severely affected, hospitality industry severely affected, in fact, a lot of the hotels, people stopped coming, and it took quite a while again to start getting them back to come. Some sporting facilities, golf clubs, foreigners stopped coming; schools were shut for a while, a lot of the hospitals were shut. That is another issue again. More people died of diseases other than Ebola.-(Male, Nigerian, Lagos State Government)

One of the most prominent observations from our study was that the perception of Ebola carried more weight than the disease itself. While Ebola is not highly contagious except at death, the media misrepresented it as a highly contagious disease, thereby reinforcing misinformation and enhanced aversion behaviour. ${ }^{2}$ People were terrified of the disease due to its high fatality rate and its misrepresentation as a highly infectious disease. All interviewees mentioned a change in consumption habits in the face of fear and misinformation during the Ebola outbreak in Nigeria. These effects of fear-based aversion behaviour and misinformation exhibited by individuals, organisations and countries led to 'fearonomic effects' on businesses and the economy. For instance, people started shopping earlier in the day to avoid crowds and the mix of goods they purchased was different compared to the period before the outbreak. People stopped going to crowded areas such as open markets, cinemas, clubs and super markets. This behaviour change was also reported in the survey (figure 4). According to our survey, $75 \%$ of respondents stayed away from crowded places, $65 \%$ decreased the use of public transport and $48 \%$ said they reduced the number of times they went to a store (figure 4).

The fear of Ebola also led to an increase in mistrust, as people were unable to freely talk to each other, hug or shake hands. These changes due to misinformation and fear-induced aversion behaviour, in turn, affected the retailers in the marketplace leading to fearonomic effects. The effects of fear-induced aversion behaviour are multidimensional, and affect the economy through distinct effects on the health and behaviour of individuals, the financial performance of businesses, and disruptions to business continuity (figure 5). While the fearonomic effects due to Ebola were inter-related and ultimately affected the entire economy, they also impacted individual lives. According to our survey, $16 \%$ of respondents reported losing jobs due to Ebola, while 


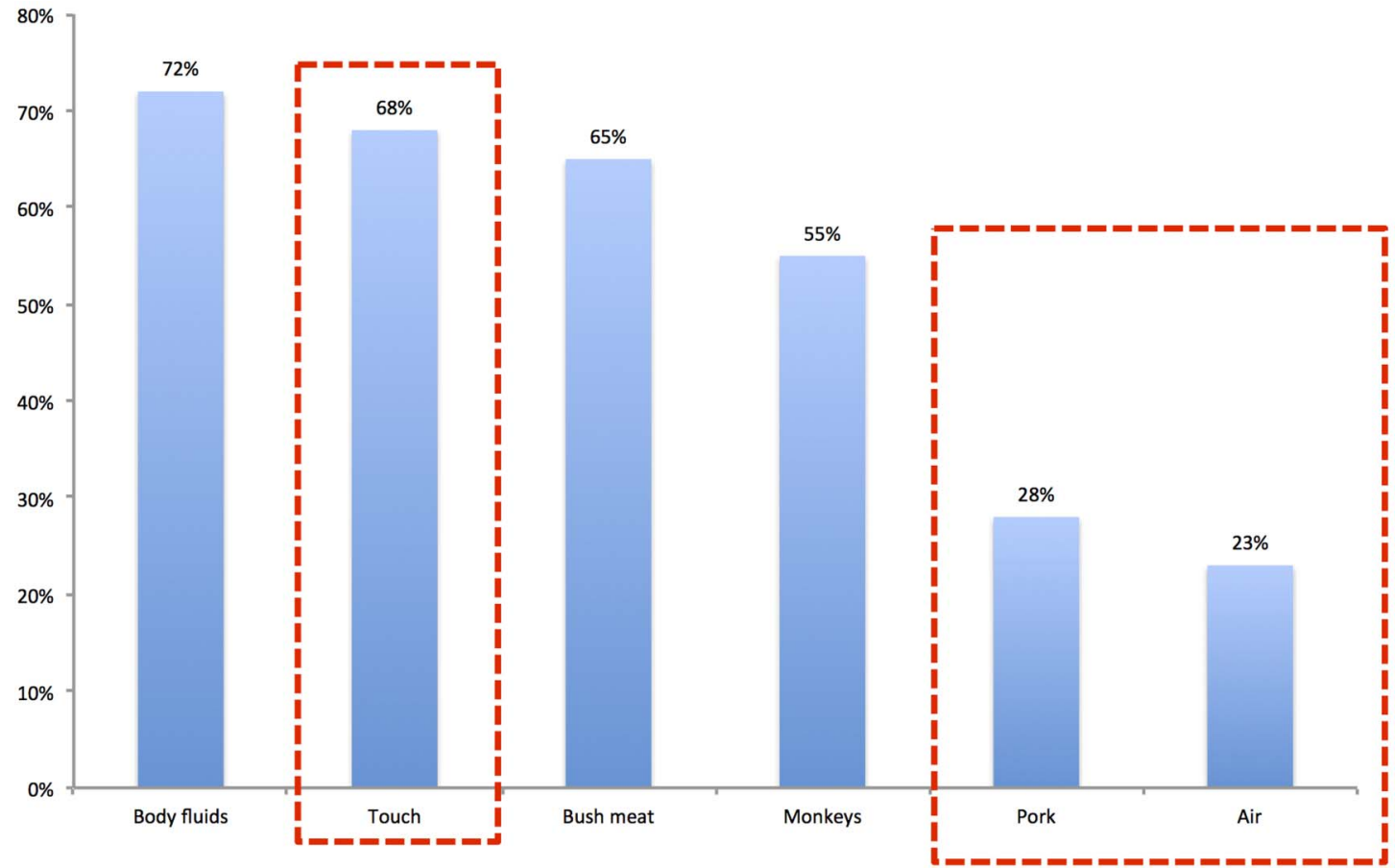

Figure 3 How is Ebola transmitted? The respondents were asked to tick all that applied on how Ebola is transmitted $(n=110)$. Red dotted lines highlight prevailing misinformation on the transmission of Ebola. About $68 \%$ respondents thought Ebola is transmitted through touch, while $28 \%$ and $23 \%$ respondents thought Ebola was transmitted through pork and air respectively. All three instances reflect the hysteria and misinformation on the transmission of Ebola.

\section{Altered social behaviour during Ebola outbreak}

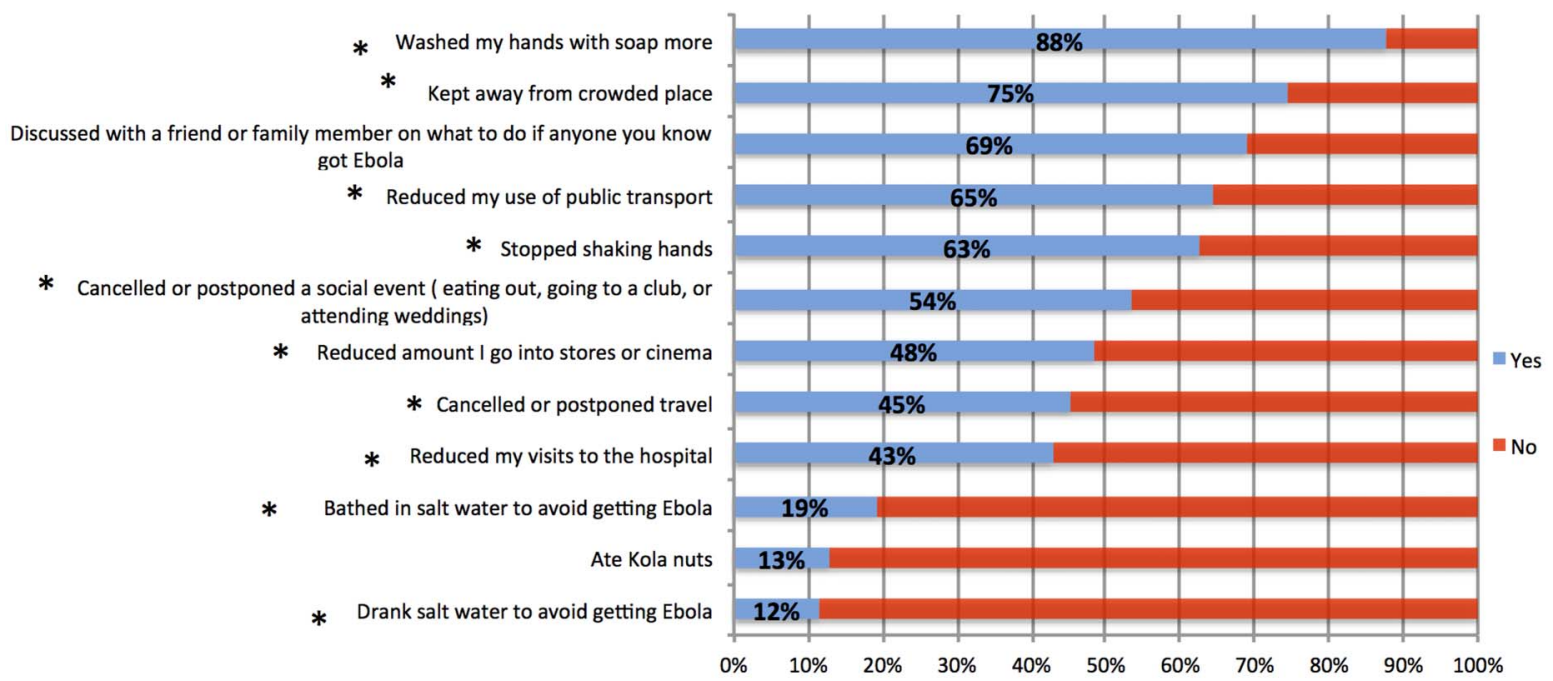

Figure 4 Altered behaviour due to fear of Ebola. Respondents were asked Yes or No, to questions on altered social habits, behaviour or visits to certain businesses during the Nigerian Ebola outbreak. Respondents were asked to tick all that applied if due to Ebola outbreak they performed the aforementioned activities. Numbers in blue represent percentage of respondents that said yes $(n=105)$ while red represents the percentage of respondents that answered no. $\left({ }^{*}\right)$ Refers to themes that were reported in the interviews. 


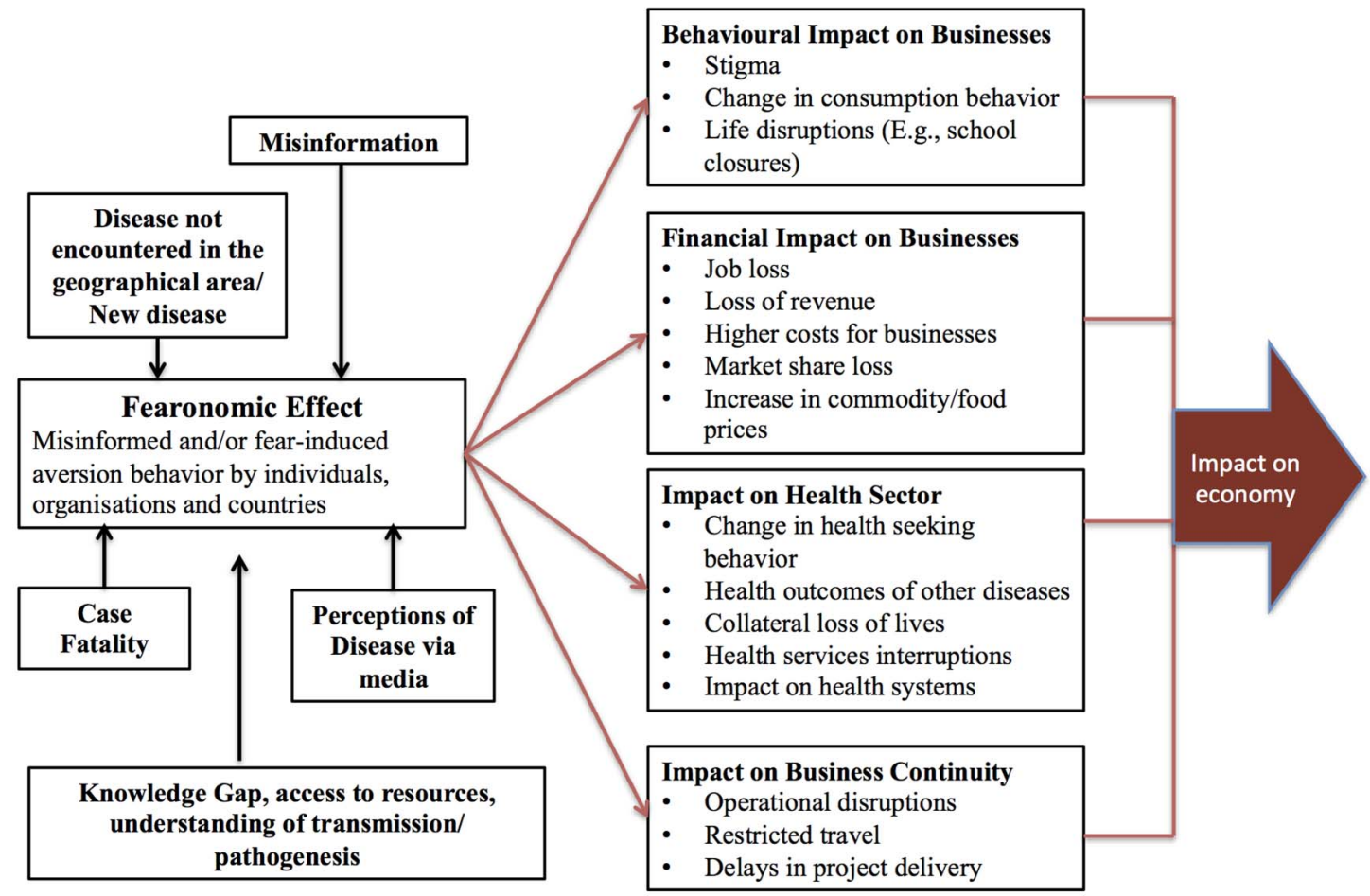

Figure 5 Framework describing the fearonomic effect of an Ebola on businesses and economy Misinformation, disease's case fatality rate, perception of disease due to media hype, knowledge gap due to disease being new to the area or a new/emerging disease are all factors that amplify fearonomic effects of an epidemic by enhancing misinformation and/or fear-based aversion behaviour. We define fearonomic effects as the direct and the indirect economic effects of both misinformation and fear-induced aversion behaviour, exhibited by individuals, organizations, or countries during an outbreak or epidemic.

$28 \%$ experienced a loss of income, $38 \%$ bought food in bulk and $29 \%$ paid higher food prices (figure 6 ). These statistics illustrate how the fearonomic effect can potentially lead to temporary financial insecurity during an epidemic.

\section{Fearonomic effects included stigma, discrimination and collateral loss of lives}

One of our housekeeping officers were ejected alongside her husband, because they believed they had Ebola, in short, they believed we all working here escaped from where we were locked up somewhere to spread the virus.(Male, Employee, Index hospital)

The tricycles wouldn't go to Obalende because everybody knew XXXX (index patient) was taken to a hospital in Obalende.-(Female, Corporate Communications Head, Foundation)

There was a doctor at XXXX hospital. It happened to be kids of hers or something, happened to be in our one only Indian school and all these parents of this Indian community said to the school that their kids would not be coming to school, we will not be sending our kids, that's one sad thing that happened.-(Male, Country Manager, Retailer)
Even as a new hands-free greeting emerged during the Ebola outbreak, heightened fear led to an increase in social mistrust. ${ }^{2} 31$ Our informants reported a decrease in trust, particularly directed towards those from poorer socioeconomic backgrounds, healthcare workers, people from Ebola-affected countries and the visibly ill. Multiple interviewees recounted cases such as that of the British Deputy High Commissioner, who lost his life to cardiac arrest when no one came forward to help him due to suspicions of Ebola. $^{32}$ Misinformation also resulted in unwarranted malicious behaviour towards individuals and businesses, endangering livelihoods or community's health. During the interviews, numerous accounts of stigma and discrimination faced by healthcare workers (HCWs), Ebola survivors and their families were shared. Our interviewees highlighted instances such as, how one of the nurses who had survived experienced stigma at a meeting when the host publicly announced that he would not hug her to protect himself. Out of fear, a landlord evicted the children of one of the victims, while the fiancée of another victim was fired after her death.

\section{Fearonomic effects included the disruption of health services}

Patients were not coming; they would stay in their houses. They prefer over the counter drugs. They don't 


\section{Fearonomic effect and aversion behaviour due to Ebola can lead to financial insecurity}

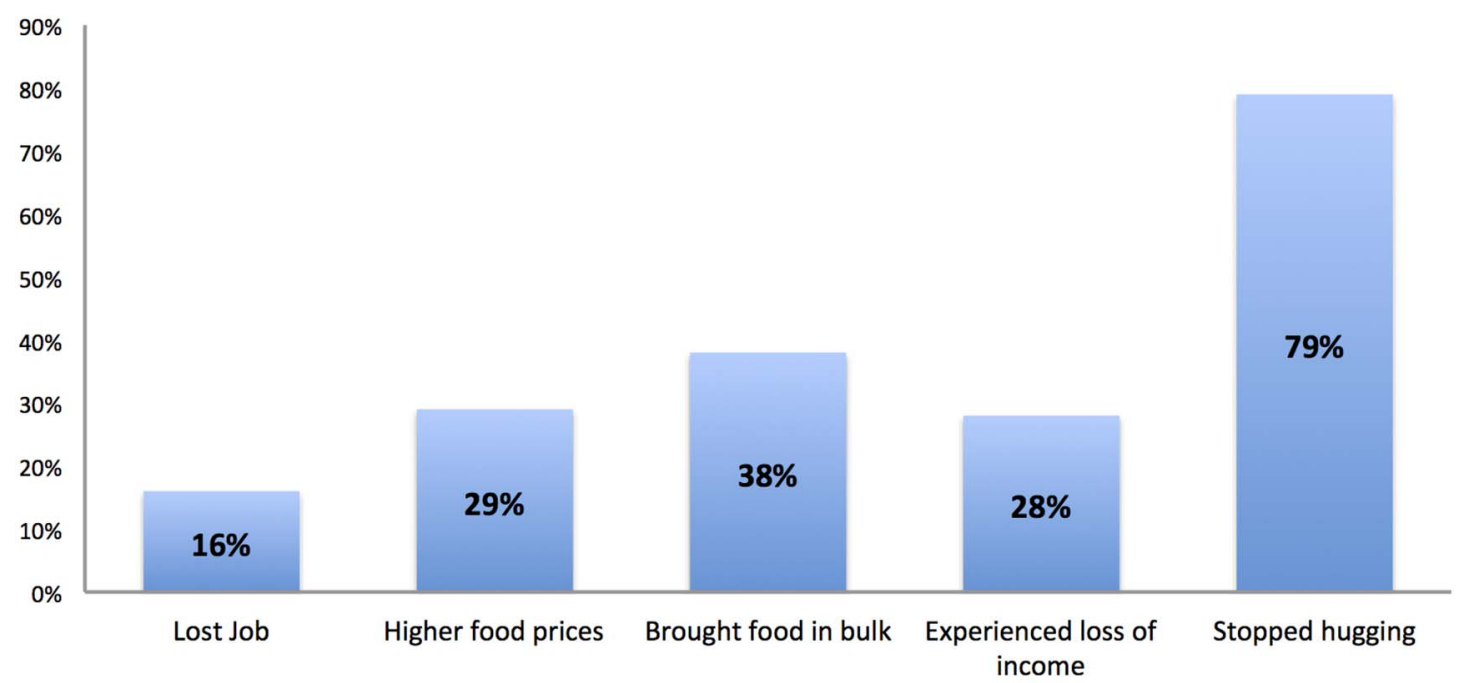

Figure 6 Fearonomic effects of an infectious disease outbreak or epidemic can lead to financial insecurity due to fear and aversion behaviour. Respondents were asked if because of Ebola they experienced any of the aforementioned options between July and October $2014(n=110)$. About $16 \%$ respondents reported losing jobs due to the Ebola outbreak, $29 \%$ respondents reported higher food prices in 2014 due to Ebola outbreak, 38\% respondents reported they brought food in bulk amount due to Ebola outbreak, $28 \%$ respondents reported loss of income due to the Ebola outbreak and $79 \%$ respondents reported they stopped hugging due to the Ebola outbreak.

come. They manage themselves at home until it is even critical that's when they come. It really affected the patients' attendance.-(Female, Head Matron, Private Healthcare Facility)

Even until now, people are still afraid of entering, but we keep on telling them that there are no traces of Ebola in here anymore.-(Medical Director, Index hospital)

Ebola-impacted Nigeria's health sector in a unique way through fear-induced aversion behaviour from both HCWs and the healthcare seekers. Hospitals suffered major financial losses due to reduced health-seeking behaviour among individuals, resulting in a sharp drop in patient volume. All hospitals interviewed reported a negative impact on revenue. The patient volume decreased by $35-50 \%$ even without a case of Ebola in the facility. One private sector hospital reported a $50 \%$ reduction in overall patient volume. In another facility, outpatient volume dropped by $35 \%$ during the outbreak, while the emergency room usage decreased by 40\%. A public sector hospital with an Ebola-infected patient reported a reduction of patient volume by 40 $50 \%$, even after the hospital was declared Ebola-free. There was significant fear of visiting hospitals. One facility recalled a case where the patient refused to have her blood pressure checked out of fear of Ebola. The fear of HCWs and hospitals was partially attributed to the uses of personal protective equipment (PPE). Patients thought the staff dealing with febrile patients looked like astronauts. The attire combined with the risk of being sent to the isolation facility exacerbated the level of fear. These qualitative findings were consistent with the survey conducted in Lagos. According to the survey, $43 \%$ of respondents mentioned they reduced their visits to hospitals more than usual (figure 4).

One of the worst affected among the healthcare facilities was Ebola's 'ground zero' in Nigeria. The facility that admitted the imported index case of Ebola in Nigeria lost key members of staff to the disease, and both its employees and the institution were subjected to stigma. Apart from the loss of expertise and capacity, the hospital lost significant market share, revenue and brand equity to the fearonomic effect of Ebola. Patient volume declined by $90 \%$ after the hospital was declared Ebola-free and a year later, only $20 \%$ of patients had returned to the facility. The aforementioned hospital was a stark example of how a leading healthcare facility could lose market share and revenue after a case of Ebola. As a result, other hospitals started turning febrile patients away, violating their obligation to provide carea phenomenon that has also been documented in the prior literature. ${ }^{33}$ Some hospitals started referring all febrile patients to the Ebola isolation facility, which could have created significant pressure on the facility if the outbreak continued over a longer period.

Owing to reduced patient volume and the resulting decrease in hospital revenues, salaries of HCWs were delayed in some facilities. This, combined with the fear of stigma and getting infected, also led to an abandonment of hospitals by HCWs and non-clinical hospital 
staff in Lagos. For example, at the hospital with the index Ebola patient, a few nurses quit their positions to escape the stigma of working with patients with Ebola. Another hospital reported the resignation of 10 staff members. Interestingly, both fear and absenteeism/ abandonment was reported to be more rampant among non-frontline medical staff than frontline staff. This could be due to non-frontline staff feeling more vulnerable without the PPE that must be provided to the HCWs.

\section{Fearonomic effects impacted on a broad range of businesses}

I had stopped selling pork because I think it was somehow related to Ebola virus, so we stopped selling pork to our customers, we stopped serving pork. We started selling only chicken and beef in our menu.(Male, Nigerian, Manager, Retail Mall)

Sales declined because people didn't go to hospitals. People were self-medicating. So sales declined but not huge.-(Male, Nigerian, Managing Director, Pharmaceutical)

Because Nigeria is a big market for all the airlines and they cannot afford to stop flying to Nigeria.-(Male, Nigerian, GM West Africa, Major International Airline)

We saw a greater demand for antibiotics.-(Male, Managing Director, Pharmaceutical).

We were not prepared for it (sanitizer demand surge) commercially because we didn't have the large volume of products to manage the situation locally. So it was during the outbreak we had to start importing. So what we could have shipped, we had to fly it down, and the cost was higher so we couldn't take advantage of the situation.(Male, Head of Compensations \& Benefits, FMCG).

As far as the average man was concerned, the world told the average man that hand sanitizers were the way to go. -(Male, National Sales Manager, Pharmaceutical company)

They were having losses during that period, so that period is not the time to lend.-(Male, Directorate Head, Lagos \& West Africa, Major Bank).

One of our vessels was suspected to be carrying an Ebola patient which was not true. Turns out to be just a fever, but because of that suspicion the vessel had to be diverted, returned back, and that was a lot of money apart from the cost of gas and cost of transportation back to Nigeria and all that was involved.-(Male Corporate Affairs, Natural Resource Company).

Despite swift control efforts, no business was immune to the fear surrounding the disease. The outbreak was a period where revenues dropped, and operating costs spiked due to investments in protection measures and staff shortages. Across all sectors, meetings were rescheduled and projects were delayed due to consultants and contractual staff's inability to travel to Nigeria out of fear. This led to opportunity costs in the form of missed commercial opportunities. For example, during our interview, a major oil and gas company estimated its cost of rescheduling meetings due to the outbreak to be US \$2-3 million, while telecom companies reported a transfer of projects to outside Africa altogether and cancellation of overseas training for Nigerian employees.

Hospitality and retail: Limited mobility coupled with fear can lead to severe negative effects particularly in service sectors such as tourism and trade. Companies involved in travel and hospitality were affected as individuals who feared infection limited their movements. Occupancy rates in two hotels interviewed dropped precipitously from $80 \%$ to $12 \%$ and $20 \%$ respectively. Another adverse effect of Ebola on the hospitality sector stemmed from online cancellations. Many hotels offer restricted discounted rates online-rates that are cheaper but are non-refundable in case of cancellation. During the outbreak, hotels had to relax their refund policy regarding cancelled bookings to include those that booked the discounted rate. Given the significant number of online cancellations, this had a drastic impact.

All three mall retailers interviewed reported a 30-40\% reduction in foot traffic, which reflected the 20-40\% decline in revenue of malls highlighted in a previous study. ${ }^{34}$ Changes in consumption and mobility also impacted retailers, restaurant owners and the informal sector as people exhibited aversion to any food products not made in front of them. Sales of street food, pork, meat and bakery were particularly affected due to fearrelated aversion behaviour and misinformation on how Ebola was transmitted. Reduced consumption of aforementioned products due to fear was highlighted in the retailer interviews and the consumer survey (figure 7).

Aviation: While international flights were halted to other Ebola-hit nations ${ }^{35} 36$ against WHO's advice, ${ }^{37}$ they continued to serve Nigeria. This was due to Nigeria's importance as a commercial hub and Nigerian government's rapid implementation of screening measures. Many airlines that continued to fly to Nigeria had stopped flying to the other three Ebola-hit countries, which were much smaller markets. The continued flights between Nigeria and the rest of the world supported the previous evidence of minimal risk of Ebola transmission through air travel with the implementation of exit screening ${ }^{38}$-Nigeria never exported a case of Ebola despite the continued flights. Nevertheless, load factors decreased drastically during the outbreak for all airlines interviewed due to the sensitivity surrounding air travel and travel restrictions on Nigerians to certain countries. As airline routes in Africa often mimic government restrictions on travel, regional airlines were the worst affected, with few routes left in operation due to travel restrictions ${ }^{39}$ on Nigerians and other Ebola- 


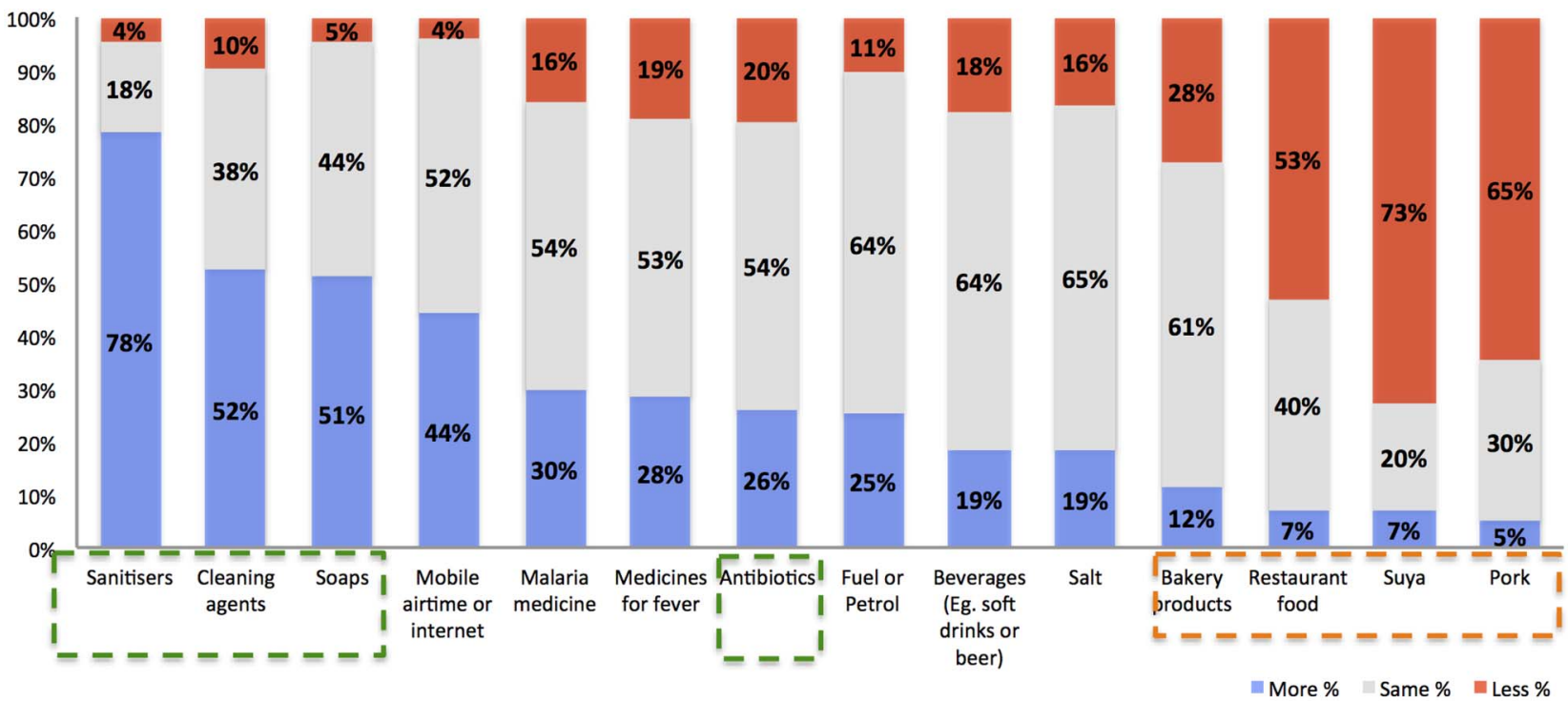

Figure 7 Change in consumer consumption behaviour during the Nigerian Ebola outbreak $(n=114)$. Respondents were asked questions if they brought certain commodities or products more or less or same during the Ebola outbreak. Blue signifies increase in purchase, red signifies decrease in purchase, while grey represents no change in purchasing habit. Numbers represents percentage of respondents out of the total respondents. The green dotted lines highlight products consumed more than usual that was also reported in the interviews. Red dotted lines highlight products consumed less than usual that were reported in the interviews as well.

affected countries. In fact, two airlines reported $40 \%$ and $70 \%$ reduction in flight occupancy of flights to and from Nigeria during the period of Ebola outbreak. Another interesting impact on the aviation sector was the change in policy regarding transport of human remains from outside Nigeria. Nigeria is a funeral society, where significant cultural importance is given to the rites of a funeral. As per our interviews, this action further decreased airline revenue since the transport of human remains represents a sizeable contribution to the overall income for a few regional carriers.

Pharmaceuticals: Despite their perceived ability to profit during an outbreak, several pharmaceutical companies incurred economic losses. Fear-induced aversion behaviour leading to lost sales for pharmaceutical industry was a major theme. One company reported an overall reduction in sales by $\sim 10-15 \%$ during the length of the outbreak. Another pharmaceutical and medical devices company highlighted how their growth rate dropped from 22 to $23 \%$ to $1 \%$ during the year of the outbreak. The reduced growth rate was attributed to both Ebola and Boko Haram attacks in the north. According to our interviewees, since patients were apprehensive of hospital visits, sales of prescription medication and medical devices dropped significantly. However, this drop in sales was offset to some extent by greater disinfectant sales and the increased sales of antibiotics, as individuals preferred self-medication to hospital visits. A marginal increase in sales of antibiotics was also observed in our consumer survey data (figure 7). The period during the Ebola outbreak in Nigeria also saw an increase in the demand for disinfectants and other products used for sterilisation. According to a pharmaceutical and medical device company, sales of products such as an effervescent Chlorine-based tablet (sodium dichloroisocyanurate), which is four times more potent than bleach for disinfection, rose by 200\% from 2013 to 2014 . Nevertheless, a $50 \%$ drop in sales was reported for other medical products (such as products for hernia, stitching, etc).

Consumer goods: Consumer goods companies were unable to translate the $200-400 \%$ surge in demand of sanitisers (figures reported in interviews) into profit because of stock-outs and higher procurement costs. The surge in demand for sanitisers overwhelmed the existing supply chain of retailers and the suppliers, who had to resort to more expensive means to meet the demand. These costs were, in turn, transferred to the consumer and led to $100-200 \%$ increase in the prices of sanitisers. ${ }^{40}$ Contrary to the popular perception that many pharmaceutical companies and consumer goods companies exploited the conditions to make profits, findings from this study reveal that increased prices was a function of more expensive alternative procurement methods to meet demand. One common method used to procure additional sanitisers was to import them quickly via air-freight from international manufactures. For example, in an interview, one supplier described flying product in from a sister factory in Indonesia, which further added to the consumer price. Another retailer flew sanitisers from London to keep up with the surge in demand.

Despite the availability of cheaper hygiene alternatives to sanitisers, misinformation on protective measures for 
Ebola led to a disproportionate increase in sanitiser demand relative to the more effective sanitiser substitutes. The alternative product manufactured by a leading Nigerian pharmaceutical and consumer goods company was supposedly superior to (if not, as effective as) sanitisers. Leveraging their brief window of opportunity during the outbreak, efforts were made to spread awareness about the product, maintain a price ceiling, eliminate stock-outs and to position the brand clearly against the alternatives. The brand tried to position itself in the market by creating pocket-friendly bottles. However, consumers seemed to be relatively unwilling to adopt this cheaper alternative disinfectant product in comparison to the sanitisers. Simply put, consumers were obsessed with hand sanitisers.

Banks: According to our findings, the one sector that fared relatively better than the rest was the banking sector, where lending practices smoothly switched over to commercial lending and there was a minor surge in new accounts. While two of the banks interviewed did not report any change in cash flow, two banks with international branches reported a minor increase in cash inflow. This could also be because people may have considered international banks more reputable and trustworthy as places to deposit their money. The increase in cash flow (in Nigeria as well as other Ebola-hit countries) was also attributed to an increase in cash transactions for humanitarian reasons and even because of fraud, as some criminals took advantage of the situation to approach people to donate to the cause of Ebola. As risk perceptions of certain sectors changed, banks became cautious in lending to small businesses, hospitals, schools and the hospitality sector. Banks significantly reduced lending to individuals and all four banks interviewed reported that they had become more careful in their lending practices during the Ebola crisis. At least two of the four banks delayed and scrutinised loan applications from people in medical fields or hospitals more closely. Furthermore, schools were shut down for 1-2 months beyond the holidays. As a result, educational institutions were also regarded as more risky clients. Other interesting observations from the banking sector were that banks reported an increase in the number of new accounts even though they had to reduce their marketing calls. The increased difficulty of securing credit by individuals and small enterprises could have potentially delayed attempts at entrepreneurship and attempts to pursue opportunities for economic growth.

Natural resources: Finally, Nigeria's most prominent sector-oil and gas-was adversely affected as well. Although the potential for loss in this sector was particularly high (due to its economic importance), the outbreak did not directly affect commercial production. Instead, most of the economic losses were traced to shipping disruptions, travel restrictions of contractual staff and the unwarranted fears of clients and suppliers in other countries. Before the interviews, a search of news accounts revealed that one supplier of ships and crew to energy producers suffered a US $\$ 6.3$ million loss due to delayed projects. ${ }^{41}$ One company interviewed reported that consignments never arrived because of the Ebola scare, leading to millions of dollars of additional costs for the company. Another company also reported an incident in which a rumour of a suspected Ebola case led to the diversion and eventual return of that vessel. This resulted in increased transportation costs for the vessel. The same company also mentioned that certain countries, such as Mexico and other developed countries, altogether stopped accepting vessels from Nigeria leading to huge costs for the company. A third company's drilling project was cancelled and their Nigerian office had to incur the cost of evacuating the staff. The cost of the outbreak was significant for the foreign joint-venture partners of the oil and gas companies in Nigeria, as they did not conduct business during that period. However, swift recovery efforts helped mitigate the impact. The stock prices of oil and gas companies were not affected as the outbreak was controlled quickly and the Nigerian state and federal governments acted proactively.

Telecom sector: While the Telecom sector was not directly affected, meetings were rescheduled, leading to delays in client engagements and finalising of contracts. One telecommunications company described how a Master's Training Programme for all of its African employees, scheduled in Seoul, was cancelled by South Korea. Another company described cancellation of a product launch due to travel restrictions. Sector's access to technical resources was limited during the period leading to delays in project delivery. A major telecommunications company from the Middle East reported that due to the inability of getting consultants to come to Nigeria, projects were stalled. Moreover, in one case, the venue of a project was moved from Lagos to Dubai.

\section{DISCUSSION}

This paper demonstrates that even when a country swiftly controls an outbreak, there can be downstream ripple effects on its economy. Importantly, these ripple effects may not be measured easily through traditional quantitative methods. The effects of fear and aversion behaviour on an economy during an outbreak have been studied previously. ${ }^{1242}$ However, this study is the first to take an in-depth look at the impact of Ebola on Nigeria's private sector, in particular. As a result, this paper builds on these earlier reports and fills an important gap in the literature. Since this study used a predominantly qualitative methodology, the aim was to seek transferability across economic sectors by using purposive sampling to capture the overall direct and indirect impact of Ebola across various sectors. As Nigeria contained the epidemic swiftly, much of the impact on the private sector has been indirect and stemming from misinformation and/or fear-induced aversion behaviour. While themes of fear, panic, stigma and misinformation 
were common across economic sectors, some sectors offered unique insights regarding altered consumption. As qualitative study renders a partial view of the whole picture, attempts were made in this study to triangulate the findings from the interviews of the private sector by complementing it with a survey conducted among consumers to understand the impact of Ebola on the private sector both from the angle of the private sector and consumers.

One of the most interesting findings from this study was the reporting of reduced health service usage as well as health service interruptions in Nigeria during the outbreak. Decreases in health service usage due to fear were also seen in Sierra Leone, Guinea and Liberia during the Ebola outbreak. ${ }^{43}$ A similar fear of HCWs by patients was also observed during the SARS epidemic due to the novelty of SARS, its nosocomial transmission and the vulnerability of HCWs to infection. ${ }^{42} 44-46$ Reduced health-seeking behaviour during the Ebola outbreak has been associated with an increase in maternal mortality in Sierra Leone ${ }^{47} 48$ as well as an increase in Malaria, HIV and TB mortality rates in other Ebola-affected countries. ${ }^{49}$ As a result, decreased health-seeking behaviour due to fears of Ebola could potentially have had a downstream effect on other health outcomes in Nigeria as well. Health service interruptions due to abandonment of hospitals by HCWs have also been reported in other outbreaks previously. Abandonment of hospital was observed during the Kikwit Ebola outbreak in Democratic Republic of Congo when all the HCWs of Kikwit General Hospital fled. ${ }^{50}$ This phenomenon is not restricted to countries in Africa. In fact, a WHO survey in the USA showed that over half of HCWs thought it acceptable not to show up for work during the Avian influenza outbreak. ${ }^{51}$ A longer Ebola outbreak could have had a significant impact on the health systems due to a loss of HCWs from disease or abandonment.

Our study highlights that Ebola's most significant effects in Nigeria stemmed from misinformation and fear-induced aversion behaviour exhibited by individuals, organisations and countries. Fear led to trade restrictions, changes in consumption patterns, the spread of rumours and an epidemic of fear. ${ }^{1257}$ This was similar to the outbreak of SARS. The indirect macroeconomic impact of SARS on the global economy was estimated to be US\$30-100 billion or US\$3-10 million per case. ${ }^{52}$ Although none of the sectors studied for this thesis were immune to the fearonomic impact of Ebola, some sectors were affected more than the others. For example, the private health sector, the aviation sector and hotels were the most affected by aversion behaviour. This is not surprising-during the SARS outbreak, a reduction in private consumption spending due to fear generated by SARS was also observed and effected the tourism, aviation and hotel sectors the most. ${ }^{45}$ Restaurants in Hong Kong experienced a sharp decline as well. $^{46}{ }^{53}$ Just like SARS, Ebola exerted a disproportionate psychological impact on people and their understanding of the disease. While this study focuses on Ebola, its findings would offer insights into the impact of future outbreaks and epidemics-in Nigeria and beyond.

Already, the spread of Zika has been met with considerable fear, fuelling the potential for significant economic repercussions. ${ }^{54} 55$ As Zika continues to spread across countries increasingly reliant on tourism (eg, Brazil, the host of the 2016 Summer Olympics, the Caribbean and more recently South-East Asia), fearonomic effects may be particularly harsh. As per one estimate by the World Bank, in 2016 itself, Zika is estimated to cost the Latin American and the Caribbean US\$3.5 billion or $0.06 \%$ of the region's GDP. ${ }^{56}$ In such a scenario, our study of fear surrounding the Nigerian Ebola outbreak offers several insights as one confronts the fearonomic effects of Zika.

Our findings highlighted that fear-induced aversion behaviour meant that open markets were almost deserted during the outbreak. Despite being a major part of the private sector, we could not study the impact of Ebola on the informal private sector due to limited time. Further research on the impact of the outbreak on the informal sector would add new insights to the study. Additional questions on the evaluation of level of fear would have further strengthened this study.

There are also a few limitations in the study, which we would like to address here. Although a consumer survey was conducted to validate and triangulate the findings, our survey data was limited in sample size due to time constraint. We did not collect information on the age or ethnicity of the interview respondents. In hindsight, such information would have added strength and further perspective to the study. Although we would have liked some documents and figures from the interviewees to support their statements, we were limited in access to the data due to concerns from the private sector. We also acknowledge that as a qualitative study, much of data is selfreported by the interviewees and there could be instances of reporting biases such as selective memory, attribution or exaggeration of risks. In some cases data shared could be difficult to independently verify. We tried to overcome these limitations by ensuring data saturation, asking questions in different ways to ensure respondent verification, interviewing different stakeholders and looking for common themes between interviews, as well as and by triangulating the findings from the interviews with consumer survey findings and prior research. We also conducted the interview in a place comfortable to the respondents in a culturally competent manner to alleviate concerns that could lead to bias in reporting.

\section{CONCLUSION}

In an era where global is the new local, the impact of epidemics is no longer limited by geographical boundaries or even economic sectors. In such a scenario, it is 
essential to battle both epidemics and their fearonomic effects to ensure epidemic resilience and prevent economic devastation due to epidemics.

Handling editor Seye Abimbola

Twitter Follow Sulzhan Bali at @sulzhan

Acknowledgements The authors would like to show their gratitude to Duke Global Health Institute for funding the field-work. The authors also thank Private Sector Health Alliance of Nigeria for their support as the on-site partner for this study. Last but not the least, thanks to all the interviewees who shared their time, insights and expertise to make this study possible.

Contributors SB and MAP were involved in conception or design of the study. MAP and KAS contributed by supervising the study. SB took part in data collection and drafted the manuscript. SB and KAS analysed and interpreted the data. MAP and KAS revised the manuscript critically for important intellectual content. SB, KAS and MAP approved the final version of the manuscript to be published.

Funding The field-work for this research was funded by Duke Global Health Institute's student field work grant for Master's Degree students.

Competing interests None declared.

Ethics approval Duke IRB.

Provenance and peer review Not commissioned; externally peer reviewed.

Data sharing statement No additional data are available.

Open Access This is an Open Access article distributed in accordance with the Creative Commons Attribution Non Commercial (CC BY-NC 4.0) license, which permits others to distribute, remix, adapt, build upon this work noncommercially, and license their derivative works on different terms, provided the original work is properly cited and the use is non-commercial. See: http:// creativecommons.org/licenses/by-nc/4.0/

\section{REFERENCES}

1. Kinsman J. "A time of fear": local, national, and international responses to a large Ebola outbreak in Uganda. Global Health 2012;8:15.

2. Ogoina D. Behavioural and emotional responses to the 2014 Ebola outbreak in Nigeria: a narrative review. Int Health 2016;8:5-12.

3. Gonsalves G, Staley P. Panic, paranoia, and public health-the AIDS epidemic's lessons for Ebola. N Engl J Med 2014;371:2348-9.

4. Hickson M, McDonald M, Meijer C, et al. Fear and stigma: the epidemic within the SARS outbreak. Emerg Infect Dis 2004;10:358-63.

5. World Bank. The economic impact of the 2014 Ebola epidemic: short and medium term estimates for West Africa. Washington, DC: World Bank Group 2014. http://documents.worldbank.org/curated/en/ 524521468141287875/The-economic-impact-of-the-2014-Ebolaepidemic-short-and-medium-term-estimates-for-West-Africa

6. Roland TM, Gregory S, Ferreira, Francisco HG, et al. The economic impact of Ebola on sub-Saharan Africa: updated estimates for 2015. Washington, DC: World Bank Group, 2015.

7. Analytica O. AFRICA: Ebola economic impact may outstrip health risk Oxford: Oxford Analytica Ltd, 2014:1.

8. Helleringer S, Grépin KA, Noymer A, WHO. Ebola virus disease in West Africa-the first 9 months. N Engl J Med 2015;372:188-9.

9. WHO. WHO Director-General summarizes the outcome of the Emergency Committee regarding clusters of microcephaly and Guillain-Barré syndrome. Secondary WHO Director-General summarizes the outcome of the Emergency Committee regarding clusters of microcephaly and Guillain-Barré syndrome. 2016. http:// www.who.int/mediacentre/news/statements/2016/ emergency-committee-zika-microcephaly/en/

10. WHO. Ebola Situation Report-2 March 2016 Secondary Ebola Situation Report-2 March 2016. 2016. http://apps.who.int/ebola/ current-situation/ebola-situation-report-2-march-2016

11. Shuaib F, Gunnala R, Musa EO, et al. Ebola virus disease outbreak -Nigeria, July-September 2014. MMWR Morb Mortal Wkly Rep 2014;63:867-72.

12. CDC. Ebola Outbreak in West Africa-Outbreak Distribution Map. Secondary Ebola Outbreak in West Africa-Outbreak Distribution
Map. 2016. http://www.cdc.gov/vhf/ebola/outbreaks/2014-west-africa/ distribution-map.html-areas

13. Baden LR, Kanapathipillai R, Campion EW, et al. Ebola-an ongoing crisis. N Engl J Med 2014;371:1458-9.

14. Moon S, Sridhar D, Pate MA, et al. Will Ebola change the game? Ten essential reforms before the next pandemic. The report of the Harvard-LSHTM Independent Panel on the Global Response to Ebola. Lancet 2015;386:2204-21.

15. Mordi F. How Nigeria beat Ebola. African business. London: IC Publications, Inc., 2014:78-9.

16. KPMG. Doing business in Africa-a focus on the business and economic impact of Ebola. South Africa: KPMG, 2015.

17. Thomas MR, Smith G, Ferreira FH, et al. The economic impact of Ebola on sub-Saharan Africa: updated estimates for 2015. 2015.

18. Vaz RG, Mkanda $P$, Banda R, et al. The role of the Polio program infrastructure in response to Ebola virus disease outbreak in Nigeria 2014. J Infect Dis 2016;213 (Suppl 3):S140-6.

19. WHO. WHO guide to identifying the economic consequences of disease and injury. World Health Organization, 2009. http://www. who.int/iris/handle/10665/137037

20. Tong A, Sainsbury P, Craig J. Consolidated criteria for reporting qualitative research (COREQ): a 32-item checklist for interviews and focus groups. Int J Qual Health Care 2007;19:349-57.

21. Strauss A, Corbin J. Grounded theory methodology. Handbook of Qualitative Research, 1994:273-85.

22. Oyeyemi SO, Gabarron E, Wynn R. Ebola, Twitter, and misinformation: a dangerous combination?. BMJ 2014.

23. Gidado S, Oladimeji AM, Roberts AA, et al. Public knowledge, perception and source of Information on Ebola virus disease-Lagos, Nigeria; September, 2014. PLOS Currents 2015. doi:10.1371/ currents.outbreaks.0b805cac244d700a47d6a3713ef2d6db

24. Jin F, Wang W, Zhao L, et al. Misinformation propagation in the age of twitter. Computer 2014;47:90-4

25. Fung $\mathrm{ICH}$, Tse $\mathrm{ZTH}$, Cheung $\mathrm{CN}$, et al. Ebola and the social media. Lancet 2014;384:2207.

26. ABCNews. Nigerian Ebola Hoax Results in Two Deaths. Secondary Nigerian Ebola Hoax Results in Two Deaths. 2014. http://abcnews.go. $\mathrm{com} /$ Health/nigerian-ebola-hoax-results-deaths/story?id=25842191

27. Griffin A. Ebola outbreak: millionaire preacher TB Joshua 'sends 4,000 bottles of holy water to Sierra Leone as cure'. Independent 17 August 2014. 2015. http://www.independent.co.uk/news/world/ millionaire-preacher-sends-4000-bottles-of-holy-water-as-ebola-cure9674136.html

28. Phillips A. Nigerian official warns pastors and healers to stop making false Ebola-cure claims. The Washington Post 31 July 2014. 2014 https://www.washingtonpost.com/news/worldviews/wp/2014/07/31/ nigerian-official-warns-pastors-and-healers-to-stop-making-falseebola-cure-claims

29. Beeching NJ, Fenech M, Houlihan CF. Ebola virus disease. BM 2014;349:g7348.

30. Prescott J, Bushmaker T, Fischer R, et al. Postmortem stability of Ebola virus. Emerg Infect Dis 2015;21:856.

31. Andrews J. Ebola: Governors Avoid Handshaking, Adopt Clenched-fist Salute. ThisDayOnline. 2014. http://www.thisdaylive. com/articles/ebola-governors-avoid-handshaking-adopt-clenched-fistsalute/186297/

32. BBC. UK diplomat dies after 'heart attack' in Lagos airport. Secondary UK diplomat dies after 'heart attack' in Lagos airport. 2014. http://www.bbc.com/news/uk-29048035

33. Maduka O, Odia O. Ethical challenges of containing Ebola: the Nigerian experience. J Med Ethics 2015;41:917-19.

34. Bank W. The economic impact of the 2014 Ebola Epidemic: short-and medium-term estimates for West Africa. Washington DC World Bank, 2014.

35. Worland J. Why One Airline Flies To West Africa Despite Ebola. Time, 2014. http://time.com/3490961/brussels-airlines-ebola/

36. Anderson M. Ebola: airlines cancel more flights to affected countries. The Guardian 201422 August, 2014. https://www.theguardian.com/ society/2014/aug/22/ebola-airlines-cancel-flights-guinea-liberiasierra-leone

37. WHO. 8th meeting of the IHR Emergency Committee regarding the Ebola outbreak in West Africa. 2015. http://www.who.int

38. Bogoch II, Creatore MI, Cetron MS, et al. Assessment of the potential for international dissemination of Ebola virus via commercial air trave during the 2014 West African outbreak. Lancet 2015;385:29-35.

39. Reuters. Travel bans issued in reaction to Ebola. Reuters, 2014.

40. Wynner E. Nigeria: Ebola Causes Scarcity, Increase in Demand for Hand Sanitizer, Other Products. 201413 August. 2014. http:// allafrica.com/stories/201408141312.htm

41. Bloomberg. Ebola Affects Bourbon's Operations As Company Swings To Loss. Secondary Ebola Affects Bourbon's Operations As 
Company Swings To Loss [438 words]. 2014. http://www.bloomberg com/news/articles/2014-09-03/bourbon-faces-ebola-damage-innigeria-amid-loss-in-first-half

42. Smith RD. Responding to global infectious disease outbreaks lessons from SARS on the role of risk perception, communication and management. Soc Sci Med 2006;63:3113-23.

43. WHO. Guidance on temporary malaria control measures in Ebola-affected countries. World Health Organization. 2014. WHO/HTM/GMP/2014.10

44. Chang $\mathrm{HJ}$, Huang $\mathrm{N}$, Lee $\mathrm{CH}$, et al. The impact of the SARS epidemic on the utilization of medical services: SARS and the fear of SARS. Am J Public Health 2004;94:562-4.

45. Fan EX. SARS: economic impacts and implications. Asian Development Bank. 2003.

46. Naylor CD, Chantler C, Griffiths S. Learning from SARS in Hong Kong and Toronto. JAMA 2004;291:2483-7.

47. Mukherjee JS, Marsh R. Excess maternal death in the time of Ebola Fletcher F World Aff 2015;39:149.

48. Ribacke KJB, van Duinen AJ, Nordenstedt $\mathrm{H}$, et al. The impact of the West Africa Ebola outbreak on obstetric health care in Sierra Leone. PLoS ONE 2016;11:e0150080.
49. Parpia AS, Ndeffo-Mbah ML, Wenzel NS, et al. Effects of response to 2014-2015 Ebola outbreak on deaths from Malaria, HIV/AIDS, and tuberculosis, West Africa. Emerging Infect Dis 2016;22:433.

50. Sokol DK. Ethics and epidemics. Am J Bioeth 2008;8:28-9.

51. Bateman C. Healthcare workers baulk at caring for contagious patients. S Afr Med J 2015;105:431-2.

52. Chou J, Kuo NF, Peng SL. Potential impacts of the SARS outbreak on Taiwan's economy*. Asian Economic Papers 2004;3:84-99.

53. Estimating the global economic costs of SARS. Learning from SARS: preparing for the next disease outbreak: workshop summary. National Academies Press. 2004. https://www.ncbi.nlm.nih.gov/books/NBK92473/

54. CNBC. Zika virus worries weigh on the travel industry. Secondary Zika virus worries weigh on the travel industry. 2016. http://www.cnbc. com/2016/02/01/zika-virus-worries-weigh-on-the-travel-industry.html

55. FoxNews. Rapidly-spreading Zika virus having financial impact on US travel industry. Secondary rapidly-spreading Zika virus having financial impact on U.S. travel industry. 2016. http://latino.foxnews. com/latino/health/2016/02/02/rapidly-spreading-zika-virus-havingfinancial-impact-on-us-travel-industry/

56. WBG. The short-term economic costs of Zika in Latin America and the Caribbean. The World Bank Group, 2016. 